\title{
Economic evaluation of exercise-based cardiac rehabilitation in patients with a recent acute coronary syndrome
}

\author{
A. J. Hautala ${ }^{1}$, A. M. Kiviniemi², T. Mäkikallio², P. Koistinen ${ }^{3}$, O.-P. Ryynänen ${ }^{4}$, J. A. Martikainen ${ }^{5}$, T. Seppänen ${ }^{1}$, \\ . V. Huikuri², M. P. Tulppo ${ }^{2}$ \\ ${ }^{T}$ Center for Machine Vision and Signal Analysis, Faculty of Information Technology and Electrical Engineering, University of \\ Oulu, Oulu, Finland, ${ }^{2}$ Medical Research Center Oulu, Oulu University Hospital and University of Oulu, Oulu, Finland, ${ }^{3}$ Social \\ and Health Services, City of Oulu, Oulu, Finland, ${ }^{4}$ Kuopio University Hospital, University of Eastern Finland, Kuopio, Finland, \\ ${ }^{5}$ Pharmacoeconomics \& Outcomes Research Unit, School of Pharmacy, University of Eastern Finland, Kuopio, Finland \\ Corresponding author: Arto J. Hautala, PhD, Center for Machine Vision and Signal Analysis, Faculty of Information Technology \\ and Electrical Engineering, P. O. Box 4500, FI-90014 University of Oulu, Finland. Tel: + 35850523 6861, Fax: ?????, \\ E-mail: arto.hautala@oulu.fi
}

Accepted for publication 28 June 2016

Health care decision-making requires evidence of the costeffectiveness of medical therapies. We evaluated the costeffectiveness of exercise-based cardiac rehabilitation (ECR) implemented according to guidelines. All the patients $(n=204)$ had experienced a recent acute coronary syndrome and were randomized to a 1-year ECR $(n=109)$ or usual care (UC) group $(n=95)$. The patients' healthrelated quality of life was followed using the 15D instrument and health care costs were collected from electronic health registries. The cost-effectiveness of ECR was estimated based on intervention and health care costs and quality-adjusted life years (QALYs) gained. The total average cost per patient was lower in ECR than in UC. The incremental cost was divided by the baseline-adjusted incremental QALYs (0.045), yielding an incremental costeffectiveness ratio of $-€ 24511 / Q A L Y s$. A combined endpoint of mortality, recurrent coronary event, or hospitalization for a heart failure occurred for five patients in ECR and 16 patients in UC (HR 3.9, 95\% CI 1.4-10.6, $P=0.004$, relative risk reduction $73 \%$, number needed to treat eight). ECR is a dominant treatment option and decreases the occurrence of adverse cardiac events. These results are useful for decision-making when planning optimal utilization of resources in Finnish health care.
Exercise-based cardiac rehabilitation (ECR) in lowrisk patients after myocardial infarction, percutaneous coronary intervention (PCI), or heart failure has reduced hospital admissions and improved health-related quality of life compared with usual care (UC) alone in many western societies (Anderson \& Taylor, 2014). ECR programs have also reduced overall premature mortality by about $20 \%$ and cardiac deaths by about $30 \%$ in comparison with UC of cardiac patients (Jolliffe et al., 2001; Taylor et al., 2004; Heran et al., 2011; Lawler et al., 2011). Despite the proven clinical effectiveness of ECR (Fletcher et al., 2013), many patients faced with a coronary artery disease (CAD) do not become or remain regularly active, mainly due to low cardiac rehabilitation referral, uptake, and adherence rates (Kotseva et al., 2013). Therefore, there is an urgent need for comprehensive ECR programs with effective risk factor management, appropriately adapted to the medical, cultural, and economic settings of a country.
The escalation of health care costs over the past years has restricted financing for expansion of ECR and prompted the need for sound evidence of the cost-effectiveness of ECR before it is taken into use more widely and incorporated into health care. ECR programs have been found to significantly reduce health care costs in the U.S.A. (Ades et al., 1992, 1997; Oldridge et al., 2008). Similarly, a German study indicated that 12-month ECR for CAD patients led to significantly less new cardiac events and improved functional capacity with lower health care cost compared with PCI-treated patients (Hambrecht et al., 2004). Although international evidence shows that ECR reduces health care costs, this information cannot be directly applied to the economic settings of each country. Health care systems, care practices, and relative prices of health care investments vary from country to country. Therefore, it is important to have country-specific data to support decision-making (Salo \& Sintonen, 2002). The aim of the present study is to assess the cost-effectiveness of 


\section{Hautala et al.}

ECR compared with UC in the Finnish health care setting.

\section{Material and methods \\ Subjects and study protocol}

The present EFEX-CARE (Effectiveness of Exercise Cardiac Rehabilitation) study has been registered at ClinicalTrials.gov, Identifier Record NCT01916525. CAD patients who suffered from acute coronary syndrome (ACS) were recruited from a consecutive series of patients in the Division of Cardiology of Oulu University Hospital. They all underwent coronary angiography to confirm the CAD. There were 876 ACS patients in the EFEX-CARE database from February 2011 through May 2014. Of those patients, 548 were excluded from the study due to the following criteria: NYHA class $\geq \mathrm{III}$, scheduled or emergency procedure for bypass surgery, unstable angina pectoris, severe peripheral atherosclerosis, diabetic retinopathy or neuropathy, or inability to perform regular home-based exercises, for example, due to severe musculo-skeletal problems. A group of patients $(n=124)$ declined to participate, for example, because of a lack of time or motivation or because of work commitments. Altogether 204 patients were willing to participate and were selected into the ECR and UC groups. In total, 109 patients in the exercise training group and 95 patients in the control group took part in the study and were included in the analyses according to the intention-totreat principle (Fig. 1). The study was carried out according to the Declaration of Helsinki, the local committee of research ethics of the Northern Ostrobothnia Hospital District approved the protocol, and all the subjects gave written informed consent.

\section{Exercise-based cardiac rehabilitation}

The ECR program started as soon as possible after hospital discharge, as suggested earlier (Pack et al., 2013). Patients willing to participate were randomized to ECR or
UC and were called about 1 week after their hospital discharge to inform them about which group they belonged to. The patients in the ECR group were invited to the Verve Rehabilitation Center (Oulu, Finland) to start the 1 -year ECR program, which included four to five exercise sessions on a weekly basis. During the first 6 months, once a week they visited our Cardiac Rehab gym equipped with aerobic and strength exercise devices (Smart Card system, Ab HUR Oy, Kokkola, Finland), where they were individually guided in both gym and home-based exercise training by a physical therapist. On the first two visits to the gym they were guided individually by a physical therapist, including instruction on use of the gym, a home-based exercise training program for the first month, how to fill in the exercise training diary, use of the perceived ratings of exertion (RPE) scale from 6 to 20 (Borg, 1982) to evaluate the average intensity of a single exercise session, a schedule for gym visits, and use of an accelerometer. Thereafter, the patients exercised in the gym in groups of no more than eight patients at the same time. However, if they needed help, a physical therapist was always available.

To improve motivation and the rate of adherence to ECR (Davies et al., 2010), we included, in addition to weekly visits to the gym, also a wrist-worn accelerometer (Polar Active, Polar Electro Oy, Kempele, Finland) in each patient's program for the first 6 months. The patients were instructed to continuously wear the accelerometer and they were able to monitor their own realized daily physical activity exceeding 3.5 metabolic equivalents (METs) from the display of the accelerometer (min/day). The physical therapist also gave feedback to the patients after each gym visit from indirectly measured peak exercise capacity during warm-up (Hautala et al., 2013). In addition, the core components of cardiac rehabilitation (Corra et al., 2010; Fletcher et al., 2013) were took into account, for example, dietary counseling for each patient or a checkup by a medical doctor when appropriate. After 6 months, home-based ECR continued and only checkpoint visits to monitor the progression of exercise training were scheduled at 9 and 12 months.

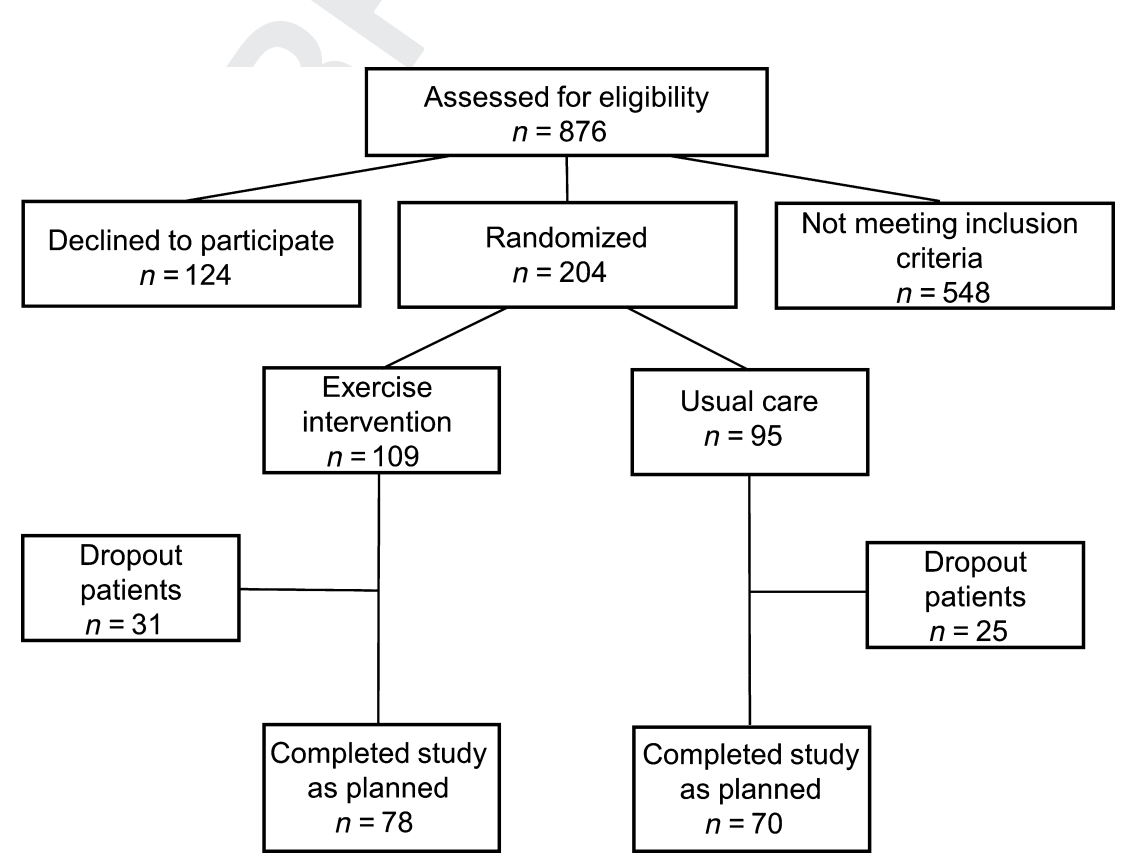

Fig. 1. Patient selection protocol from the EFEX-CARE database. 
Exercise and cost-effectiveness

The exercise training was planned according to the current guidelines (Corra et al., 2010; Fletcher et al., 2013). The 1-year exercise training intervention consisted of home-based aerobic (30-40 $\mathrm{min})$ and strength exercises (30-40 min). The intensity of the aerobic exercises was stated as between 12-15 RPE and it consisted of walking, running, cycling, or cross-country skiing. The strength exercises were circuit training targeted at the body's major muscle groups at moderate intensity $(2-3 \times 7$ sets, $\geq 10$ repetitions/ set) targeted at 13 RPE. During the first 6 months on a weekly basis, and at the time points of 9 and 12 months, the controlled strength exercise session at the gym included (duration $30-45 \mathrm{~min} / \mathrm{session}$ ) $7 \mathrm{~min}$ of warm-up on a bicycle and 1-3 sets of fifteen repetitions at the intensity of 13 RPE, followed by $5 \mathrm{~min}$ of cool-down. Single exercises for the lower extremity included leg presses and leg extensions curls; for the upper extremity, chest presses, pushups/pulldowns, and dips/shrugs; and for the middle, abdomen/back exercises and twists. The patients were given a diary in which training days were marked with the target duration and intensity of the exercises. After each exercise session, they marked the realized training mode, duration, and mean RPE in the diary. A physical therapist checked the diaries after 1, 3, 6, and 9 months and gave them a new training program for the following months.

Monthly realized training load was calculated from the diaries by calculating training load $(\mathrm{RPE} \times$ duration of exercise session), described earlier (Foster, 1998). Both groups were treated according to Current Care Guidelines defined by a working group appointed by the Finnish Medical Society Duodecim and the Finnish Cardiac Society (Porela et al., 2015). The patients in the UC group did not get any individually tailored exercise prescriptions.

\section{Assessment of baseline exercise capacity}

All the patients performed an incremental symptom-limited maximal exercise test (Oulu University Hospital, Oulu, Finland) on a bicycle ergometer (Monark Ergomedic 839 E; Monark Exercise AB, Vansbro, Sweden) for assessment of exercise capacity (Table 1). The test was started at $30 \mathrm{~W}$, and the work rate was increased by $15 \mathrm{~W}$ in men and $10 \mathrm{~W}$ in women every minute until voluntary exhaustion or ST depression $>0.2 \mathrm{mV}$ in ECG was reached (CAM-14; GE Healthcare, Freiburg, Germany). Maximal workload was calculated as the average workload during the last minute of the test and maximal exercise capacity was then calculated in METs from the maximal workload.

\section{Measurements of baseline characteristics}

Body composition was assessed by measurements of weight and body mass index. Blood pressure was measured in a supine position after a 10 -min resting period. The Depression Scale (DEPS) questionnaire was used to assess self-rated depression (Salokangas et al., 1995). Smoking status, history of acute myocardial infarction, and revascularization and medication were defined from the hospital registry and standard questionnaires. Left ventricular systolic function was assessed using 2-D echocardiography (Vivid 7; GE Healthcare, Wauwatosa, Wisconsin, U.S.A.). Fasting blood samples were obtained for analysis of plasma glucose and glycated hemoglobin (HbAlc) levels, insulin, blood lipids, and high-sensitivity C-reactive protein after a $12-\mathrm{h}$ overnight fast using standardized methods (Oulu University Hospital, Oulu, Finland).
Table 1. Baseline demographics, clinical characteristics, and medication use according to the intention-to-treat principle

\begin{tabular}{|c|c|c|}
\hline Variable & $\begin{array}{l}\text { Rehabilitation } \\
(n=109)\end{array}$ & $\begin{array}{l}\text { Usual care } \\
(n=95)\end{array}$ \\
\hline Men, $n$ & $80(73 \%)$ & $67(71 \%)$ \\
\hline Patients with T2D, $n$ & $24(22 \%)$ & $17(18 \%)$ \\
\hline Age, years & $60 \pm 11$ & $62 \pm 9$ \\
\hline Weight, kg & $81 \pm 15$ & $83 \pm 16$ \\
\hline $\mathrm{BMI}, \mathrm{kg} / \mathrm{m}^{2}$ & $27.6 \pm 4.3$ & $28.0 \pm 4.6$ \\
\hline Systolic BP, mmHg ${ }^{*}$ & $136 \pm 22$ & $139 \pm 24$ \\
\hline Diastolic BP, mmHg ${ }^{*}$ & $77 \pm 11$ & $79 \pm 11$ \\
\hline $\begin{array}{l}\text { Exercise } \\
\text { capacity, MET* }\end{array}$ & $6.0 \pm 1.7$ & $5.7 \pm 1.7$ \\
\hline Depression score* & $5.2 \pm 5.3$ & $4.8 \pm 5.2$ \\
\hline $\begin{array}{l}\text { Current smokers, } n \\
\text { History of AMI }\end{array}$ & $16(15 \%)$ & $16(17 \%)$ \\
\hline NSTEMI, $n^{\star}$ & $47(48 \%)$ & $45(58 \%)$ \\
\hline STEMI, $n^{\star}$ & $44(45 \%)$ & $28(36 \%)$ \\
\hline \multicolumn{3}{|l|}{ Revascularization } \\
\hline $\mathrm{PCl}, n$ & $95(87 \%)$ & $83(87 \%)$ \\
\hline Earlier CABG, $n$ & $5(5 \%)$ & $8(8 \%)$ \\
\hline \multicolumn{3}{|l|}{ Cardiac function } \\
\hline LVEF, \%* & $62 \pm 8$ & $62 \pm 8$ \\
\hline CCS class* & $1.4 \pm 0.6$ & $1.6 \pm 0.6$ \\
\hline \multicolumn{3}{|l|}{ Laboratory analyses } \\
\hline $\mathrm{HbA1c}, \% *$ & $6.0 \pm 0.8$ & $6.0 \pm 0.9$ \\
\hline $\begin{array}{l}\text { Fasting plasma } \\
\text { glucose, } \mathrm{mmol} / \mathrm{L}^{*}\end{array}$ & $6.0 \pm 1.0$ & $6.0 \pm 0.9$ \\
\hline $\begin{array}{l}\text { Total cholesterol, } \\
\mathrm{mmol} / \mathrm{L}^{*}\end{array}$ & $3.8 \pm 0.8$ & $3.8 \pm 0.7$ \\
\hline $\begin{array}{l}\text { HDL cholesterol, } \\
\mathrm{mmol} / \mathrm{L}^{*}\end{array}$ & $1.2 \pm 0.3$ & $1.3 \pm 0.3$ \\
\hline $\begin{array}{l}\text { LDL cholesterol, } \\
\mathrm{mmol} / \mathrm{L}^{*}\end{array}$ & $2.2 \pm 0.7$ & $2.1 \pm 0.7$ \\
\hline $\begin{array}{l}\text { Triglycerides, } \\
\mathrm{mmol} / \mathrm{L}^{*}\end{array}$ & $1.5 \pm 1.2$ & $1.3 \pm 0.6$ \\
\hline hs-CRP, mg/L* & $2.3 \pm 4.2$ & $2.5 \pm 5.5$ \\
\hline \multicolumn{3}{|l|}{ Medication } \\
\hline Beta blockers, $n$ & $91(83 \%)$ & $83(87 \%)$ \\
\hline ACEI or ARB, $n^{\star}$ & $87(90 \%)$ & $67(86 \%)$ \\
\hline Lipids, $n^{\star}$ & $95(98 \%)$ & $77(99 \%)$ \\
\hline Anticoagulants, $n^{*}$ & $97(100 \%)$ & $77(99 \%)$ \\
\hline $\begin{array}{l}\text { Calcium } \\
\text { antagonists, } n^{\star}\end{array}$ & $16(16 \%)$ & $20(26 \%)$ \\
\hline Nitrates, $n^{\star}$ & $21(22 \%)$ & $22(28 \%)$ \\
\hline Diuretics, $n^{\star}$ & $13(13 \%)$ & $17(22 \%)$ \\
\hline
\end{tabular}

Values are means $\pm S D$ or the number of subjects (proportion).

T2D, type 2 diabetes; BMI, body mass index; BP, blood pressure; MET, metabolic equivalent; AMI, acute myocardial infarction; NSTEMI, nonST segment elevation myocardial infarction; STEMI, ST segment elevation myocardial infarction; $\mathrm{PCl}$, percutaneous coronary intervention; $\mathrm{CABG}$, coronary artery bypass grafting; LVEF, left ventricular ejection fraction; CCS, Canadian Cardiovascular Society grading of angina pectoris; HbA1c, glycated hemoglobin; HDL, high-density lipoprotein; LDL, low-density lipoprotein; hs-CRP, high-sensitivity C-reactive protein; ACEI, angiotensin conversion enzyme inhibitor; ARB angiotensin receptor blocker.

${ }^{\star} n$ for the rehabilitation group $=97$ and for the control group $=78$.

\section{Health-related quality of life}

Quality-adjusted life years (QALYs) were used as a generic measure of effectiveness. Estimates of QALYs were derived from the 15D questionnaire (Sintonen, 2001), which was 


\section{Hautala et al.}

completed by the participants at the baseline, after 6 months, and after 1 year. The $15 \mathrm{D}$ is a generic, standardized, self-administered 15D instrument intended for measuring health-related quality of life in adults. It can be used both as a profile and as a single index score measure. The 15D consists of fifteen dimensions: mobility, vision, hearing, breathing, sleeping, eating, speech, elimination, usual activities, mental function, discomfort and symptoms, depression, distress, vitality, and sexual activity. Each dimension has five levels of severity, varying from no problem to extreme difficulties (Saarni et al., 2006). The 15D represents continuous utility scores between 0 (dead) and 1 (full health). The generic minimum important change in $15 \mathrm{D}$ scores is \pm 0.015 (Alanne et al., 2015). The 15D compares favorably with other preference-based generic instruments in the important properties (reliability, validity, discriminatory power, and responsiveness to change). The $15 \mathrm{D}$ has been validated among several patient groups, including coronary heart disease (Kontodimopoulos et al., 2012).

All the patients filled in the 15D questionnaire at the hospital before hospital discharge. The ECR group filled in the questionnaire during their follow-up visits to the gym at 6 and 12 months. For the UC group, the questionnaire was mailed and the filled questionnaire was returned by mail. The $15 \mathrm{D}$ scores were converted to utility scores. The utility estimates were converted to adjusted mean QALYs by calculating the area under the curve of utility estimates for each patient, using the multiple regression model to control for baseline utility differences (Manca et al., 2005).

\section{Health care costs}

Cost estimation was done taking into account both specialized and primary health care services. The costs of occupational health care services and exercise training intervention costs were also collected. As the majority of the patients were retired $(51 \%)$, productivity losses due to illness-related absence from the workplace were not estimated.

Health care costs arising from the use of health services were obtained on the part of specialized health care using social security ID numbers to determine visits for ambulatory care, number of treatment days, and use of external services. These were measured on the basis of invoicing (by utilizing diagnosis-related groups classification). The cost of using primary health care was obtained from electronic health registries using unique social security ID numbers to determine visits to the doctor, other significant examinations (e.g., large $\mathrm{x}$-rays, etc.), and in-ward treatment days. In addition, the use of home care and possible institutional care (e.g., assisted care home, etc.) was determined from registries. Occupational health care service costs were estimated according to the report of the Social Insurance Institute of Finland (KELA) (Hujanen \& Mikkola, 2013). The cost of ECR was estimated according to the average monthly fees in Finnish gyms where individual guidance in exercise training is led by a health care professional, for example, a physical therapist. These kinds of concepts of rehabilitation may include the use of diaries or accelerometers, for example. All costs were handled as 2015 values. Due to the 1-year time horizon of the analysis, no discounting was applied.

\section{Cost-effectiveness analysis}

The incremental cost-effectiveness ratio (ICER) was estimated $\left(\mathrm{ICER}=\left[\right.\right.$ Cost $_{\mathrm{ECR}}$ group - Cost $\left._{\mathrm{UC} \text { group }}\right] /\left[\right.$ Effectiveness $\mathrm{ECR}_{\mathrm{E} \text { group }}$ - Effectiveness ${ }_{\mathrm{UC}}$ group]) to compare costs and outcomes (effectiveness) between groups according to the intention-totreat principle. Incremental cost was determined by the difference in total average cost per patient between the ECR and UC groups. Incremental effectiveness was estimated by the baselineadjusted incremental QALYs.

\section{Major adverse cardiac event}

A major adverse cardiac event (MACE) was defined as a combination of death, recurrent acute coronary event, or hospitalization for heart failure. The follow-up data of 1 year were collected from the patient records of Oulu University Hospital.

\section{Statistical analyses}

All the patients who gave their written informed consent for the study were included in the analyses according to the intention-to-treat principle. Descriptive statistical analyses were conducted using means, standard deviations (SDs), and proportions, as appropriate. Dropouts were analyzed by logistic regression. To perform an intention-to-treat analysis, we imputed missing data using two methods.

1. last observation carried forward (replacing $15 \mathrm{D}$ data at 12 months with corresponding data from the 6-month follow-up), and

2. Bayesian network to predict $15 \mathrm{D}$ data in missing cases if the 6-month follow-up was not available.

The imputation was done with Bayesialab Academic edition (Laval Cedec, France, www.bayesialab.com), using a structural expectation maximization (structural EM) algorithm (Missing values imputation) (SAS).

A non-parametric bootstrapping approach was applied to define mean values and 95\% confidence intervals for costs and QALYs at 12 months. In addition, paired non-parametric bootstrapping was applied to estimate sampling uncertainty around the ICER estimate. The results of this analysis were depicted on a cost-effectiveness plane characterizing the joint distribution of incremental costs and QALYs around the ICER value. Furthermore, the probability of cost-effectiveness when taking into account sampling uncertainty was characterized by a cost-effectiveness acceptability curve (CEAC) (Fenwick et al., 2004). After the 1year intervention, univariate Cox regression was used to estimate hazard ratios (HRs) with 95\% confidence intervals (CIs) for the association between the groups and the MACE outcome.

Kaplan-Meier survival curves were plotted to examine differences in cumulative MACE across the groups. We also calculated the number needed to treat (NNT) (Laupacis et al., 1988; Cook \& Sackett, 1995), which provides an estimate of the number of patients who need to rehabilitate in ECR to prevent an additional MACE. Statistical analyses of the data were performed with SPSS software (SPSS 22, SPSS Inc., Chicago, Illinois, U.S.A.) and STATA 9.0 (Stata Corp. LP, College Station, Texas, U.S.A.). Statistical significance was defined as a $P$-value $<0.05$ for all tests.

\section{Results}

Baseline demographics, clinical characteristics, and medication use of the study participants are illustrated in Table 1. In the ERC group, the average of monthly realized exercise training (training load 
$15995 \pm 8076)$ exceeded the prescribed training (training load $10727 \pm 475)$ by $49 \%(P<0.0001)$.

During the 1-year intervention, 31 patients $(28 \%)$ in the ECR group and 25 in the UC group (26\%) dropped out from the study mainly due to a lack of motivation (Fig. 1). In a logistic regression analysis, being a dropout was associated with younger age $(P=0.004)$ and lower BMI $(P=0.009)$. More specifically, in the ECR group the reasons for interruption were loss of interest (17), logistic problems (5), loss of time mainly because of work duties (5) or health-related problems (4). In the UC group, dropout patients reported loss of interest (18), loss of time (5), or health-related problems (2). However, the dropout rate did not differ between the groups $(P=0.638)$. The Kaplan-Meier survival curve shows a statistically significant difference in incidence of MACE between the groups (Fig. 2).

\section{Health care costs and quality-adjusted life years}

The total average cost per patient in the ECR group showed a tendency of being lower in the ECC group $(€ 1944)$ than in the UC group (€3027), when analyzed according to the intention-to-treat principle (Table 2). In patients who completed the intervention as planned, the total average cost per patient was lower in the ECR group (€1652) than in the UC group (€2629). In the ECR group, quality of life showed a minor increase (average change in QALYs $0.013)$, whereas in the UC group, quality of life deteriorated (average change in QALYs -0.012) during the study period according intention-to-treat analysis.

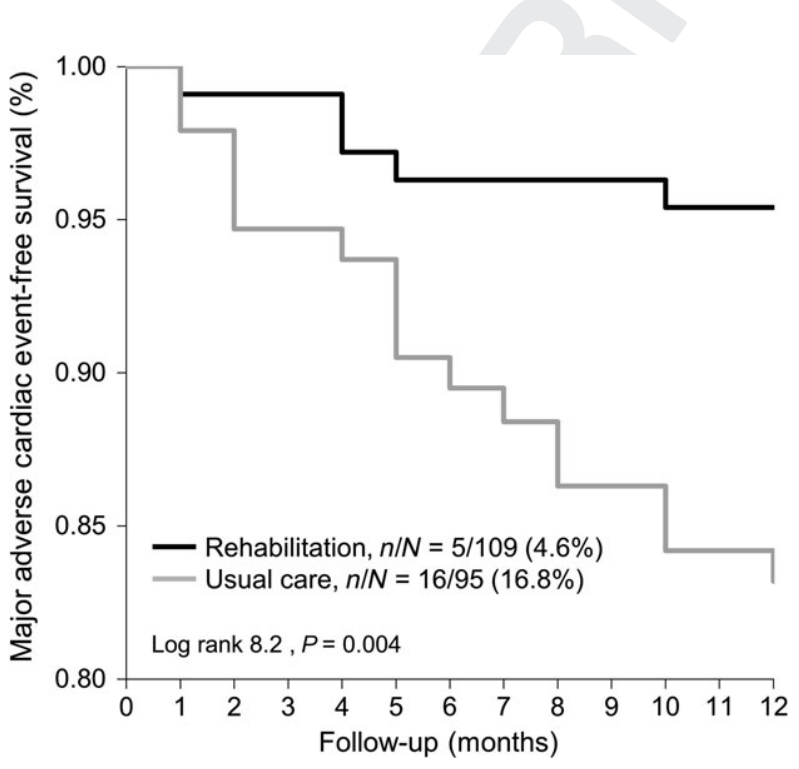

Fig. 2. Kaplan-Meier survival curves of the groups as predictors of a composite end point of cardiovascular death, acute coronary event, or hospitalization for heart failure.

\section{Cost-effectiveness}

The cost-effectiveness analysis demonstrated that the ECR program was both less costly and more effective than the UC alone, regardless of the applied data set (i.e., data with and without imputation of missing utility data). These findings were confirmed with the cost-effectiveness plane (Fig. 3), where the majority of bootstrapped replications (i.e., the joint distribution of incremental costs and QALYs) located in the southeast quadrant (i.e., indicating that ECR is less costly and more effective compared with UC alone).

A cost-effectiveness acceptability curve demonstrated that ECR is cost-effective with any value of willingness to pay (data not shown). The incremental cost was divided by the baseline-adjusted incremental QALYs (0.045), yielding an incremental costeffectiveness ratio of -€24 511/QALYs.

\section{Discussion}

The present cost-effectiveness study demonstrated that the addition of 1 year of regular exercise training to UC according to current guidelines was a dominant treatment option (i.e., less costly and more effective) and reduced the occurrence of adverse cardiac events compared with UC alone. The additional health benefits provided by the ECR program, reflected in the ECR group's reduced rate of cardiovascular adverse events, may have been responsible for the trend observed in the changes in quality of life between the ECR and UC groups over the intervention period of 1 year.

\section{Health-related quality of life}

We used the $15 \mathrm{D}$ as a generic and comprehensive measure of health-related quality of life, where a single index score represents overall health-related quality of life on a $0-1$ scale $(1=$ full health, $0=$ being dead) (Sintonen, 2001). The average baseline value of the $15 \mathrm{D}$ index score in our study population was high (0.905), which may indicate that acute care and medication were well accepted or our post-ACS patients were stable or asymptomatic at the baseline. However, similar values of index scores (0.91) have also been reported in patients with ST-elevated myocardial infarction (Bohmer et al., 2014); respectively, high baseline values mean that expected positive changes in health-related quality of life cannot be large, which was also shown in the present study. It is also notable that baseline QALYs did not differ between the ECR and UC groups (0.908 vs 0.908$)$ in the present study. Instead, the decline in QALYs almost exceeded the clinically or practically important minimum change in 0.015 in the UC group 


\section{Hautala et al.}

Table 2. Costs, QALYS gained, and the cost-effectiveness of exercise-based cardiac rehabilitation intervention in patients with a recent acute coronary syndrome

\begin{tabular}{|c|c|c|c|c|}
\hline \multirow[t]{2}{*}{ Description of resource } & \multicolumn{2}{|l|}{ Rehabilitation } & \multicolumn{2}{|l|}{ Usual care } \\
\hline & $\begin{array}{l}\text { Mean (without } \\
\text { imputation; } n=78 \text { ) }\end{array}$ & $\begin{array}{l}\text { Mean (with } \\
\text { imputation; } n=109 \text { ) }\end{array}$ & $\begin{array}{l}\text { Mean (without } \\
\text { imputation; } n=70 \text { ) }\end{array}$ & $\begin{array}{l}\text { Mean (with } \\
\text { imputation; } n=95 \text { ) }\end{array}$ \\
\hline Primary health care costs $(€)$ & 346 & 357 & 418 & 483 \\
\hline Secondary health care costs $(€)$ & 814 & 1162 & 2142 & 2479 \\
\hline Occupational health care service costs $(€)$ & 117 & 126 & 69 & 65 \\
\hline Exercise-based cardiac rehabilitation costs $(€)$ & 375 & 299 & 0 & 0 \\
\hline Total average cost per patient $(€)$ & 1652 & 1944 & 2629 & 3027 \\
\hline Incremental cost $(€)^{*}$ & $\begin{array}{l}-865 \\
(-1765 \text { to }-119)\end{array}$ & $\begin{array}{l}-1103 \\
(-2249 \text { to }-49)\end{array}$ & & \\
\hline Average utility at the baseline & 0.917 & 0.908 & 0.897 & 0.900 \\
\hline Average change in $15 D$ utility & -0.008 & 0.013 & -0.020 & -0.012 \\
\hline Baseline-adjusted mean QALYs at 12 months $^{\dagger}$ & 0.909 & 0.922 & 0.878 & 0.885 \\
\hline Adjusted incremental QALYs gained* & $\begin{array}{c}0.037 \\
(0.028-0.047)\end{array}$ & $\begin{array}{c}0.045 \\
(0.023-0.077)\end{array}$ & & \\
\hline ICER & Dominant option & Dominant option & & \\
\hline
\end{tabular}

${ }^{*}$ Means and $95 \% \mathrm{Cls}$ are estimated using non-parametric bootstrapping.

${ }^{\dagger}$ QALYs adjusted for baseline 15D utility using regression-based adjustment; R, rehabilitation; UC, usual care; QALY, quality-adjusted life year; ICER, incremental cost-effectiveness ratio.

${ }^{\ddagger}$ Intervention is less costly and more effective.

(-0.012) (Alanne et al., 2015), but was the opposite in the ECR group (0.013).

\section{Cost-effectiveness}

In the current era of restrictions on health care budgets, there is an urgent need for alternative care strategies that prove to be cost-effective. Although ECR has proven an effective and safe therapy for use

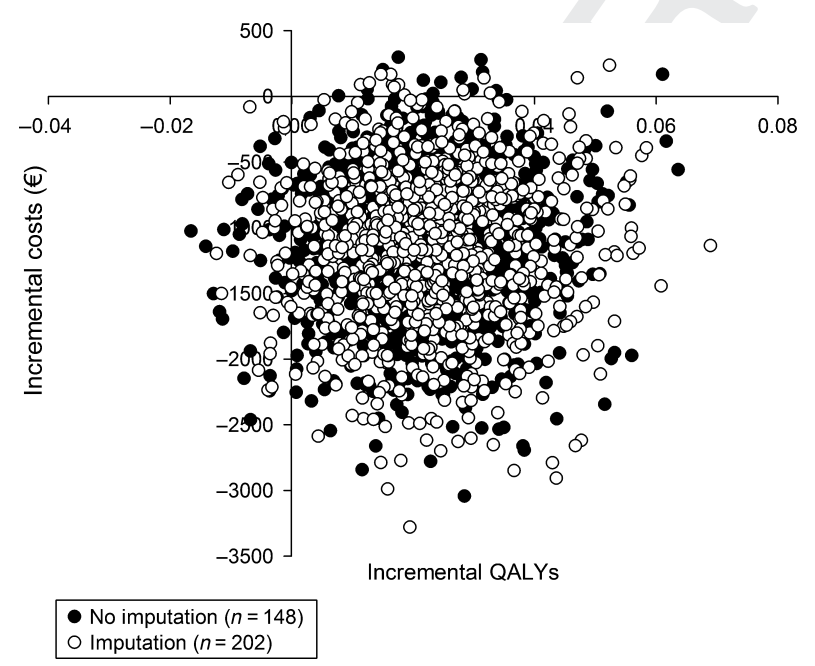

Fig. 3. Cost-effectiveness plane showing the joint distribution of incremental costs and effects (from the trial data using 1000 bootstrap replicates) when comparing exercisebased cardiac rehabilitation (ECR) intervention with usual care in patients with a recent acute coronary syndrome. The most bootstrap replications lie on the southeast quadrant, indicating that ECR is a less costly and more effective treatment option. in the management of stable CAD patients when compared with a no exercise training control (Anderson \& Taylor, 2014), ECR is underused, with poor referral and a low participation rate (Kotseva et al., 2013). From the economic point of view, the EUROASPIRE data on CAD patients showed that the effects of optimized tailored prevention (smoking cessation, diet and exercise, better management of elevated blood pressure, and/or low-density lipoprotein cholesterol) is cost-effective compared with the current degree of cardiovascular prevention with an ICER of €12 484/QALYs (De Smedt et al., 2012). The best results were found in elderly patients and patients with high blood pressure or who are not physically active. ECR programs have been found to significantly lower health care costs in the U.S.A. (Ades et al., 1997; Oldridge et al., 2008). Furthermore, in a systemic review of economic evaluations of ECR programs, it was observed that supervised (or center-based) or home-based cardiac rehabilitation was cost-effective compared with UC (Wong et al., 2012).

The cost-effectiveness study by Frederix et al. (2015) showed that center-based ECR was even more effective and efficient with incorporation of a cardiac telerehabilitation program than conventional centerbased ECR alone during a 1-year follow-up. The conventional center-based ECR lasted 12 weeks and the telerehabilitation program lasted 24 weeks. Both groups were instructed to exercise 45-60 $\mathrm{min} / \mathrm{session}$ at the predefined target heart rate in at least two training sessions per week. The telerehabilitation group patients were instructed to wear an accelerometer continuously and to transmit their realized 
physical activity data weekly to the local server for providing the patients' feedback encouraging them to achieve predefined exercise training goals. They found that the total average cost per patient was significantly lower in the telerehabilitation group than in a conventional ECR group with an ICER of -€21 707/QALYs. In addition to home-based selfmonitoring of physical activity by accelerometers, our ECR concept included structured physical therapist contacts and a weekly strength training session during the first 6 months, with feedback discussions, early appointments after discharge, and an individually guided exercise training program, which all are reported to be parts of successful interventions in cardiac rehabilitation programs (Karmali et al., 2014). We reported an ICER of -€24 511/QALYs, which emphasizes the ECR program of 1 year according to current guidelines as a dominant option. This information may be useful for policymakers charged with deciding how limited health care resources should be allocated best in the Finnish health care system.

\section{Exercise training and cardiovascular outcome}

As mentioned earlier, the role of regular exercise training in the prevention of cardiovascular events and mortality in CAD patients has been well established (Hammill et al., 2010; Heran et al., 2011; Lawler et al., 2011). Some concerns about the effects of ECR in the current era of care have been raised because of simultaneous major advances in cardiovascular science and medicine (Nabel \& Braunwald, 2012). However, a recent overview of Cochrane systematic reviews confirms that ECR reduces the risk of mortality or future hospitalizations compared with a no exercise training control in clinically stable CAD patients after myocardial infarction or PCI (Anderson \& Taylor, 2014). The present study also showed a clear relative risk reduction $(73 \%)$ of MACE in favor of ECR. We also provided an alternative measure (NNT) for expressing the information conveyed in the absolute risk reduction, permitting a comparison of the benefits and risk associated with the ECR approach presented. The estimated NNT for MACE in the present study was 8 , which is very low. Schwaab et al. (2011) reported an NNT of 17 for the primary endpoint of mortality, myocardial infarction, and revascularization in a study setup, where 3-week inpatient cardiac rehabilitation in ACS was performed followed by a follow-up of 1 year. Taken together, with the very low NNT shown in the present study, ECR is highly effective and should be advised for all suitable patients with ACS.

\section{Adherence to exercise training}

In the present study, the dropout rate from the exercise training program (on average 27\%) was on about a similar level as in some previous studies. In our previous ECR study of a 2-year intervention in CAD patients with and without type 2 diabetes, the dropout rate was about 37\% (Karjalainen et al., 2014). Similarly, Marzolini et al. (2008) demonstrated that non-completion of a 12-month cardiac rehabilitation program averaged $32 \%$, whereas $42 \%$ of patients did not complete the cardiac rehabilitation program in a study by Sanderson et al. (2003). Interestingly, the patients who completed the ECR intervention of 1 year exceeded the prescribed training load clearly $(49 \%)$. This may, at least partly, emphasize the successful implementation of components described in the literature, for example, self-monitoring of physical activity and tailored counseling by a physical therapist (Karmali et al., 2014) on a weekly basis during first 6 months with the purpose of motivating weekly exercise training and increased adherence.

\section{Strengths and limitations}

Strengths of this study were that the data on use of health care services were derived from hospital records, rather than patient self-reports, thereby eliminating recall bias. The health-related quality of life data were collected directly from the participants using a tool suitable for CAD patients (Kattainen et al., 2006). Secondly, the patients in the present study were very widely characterized at the baseline, including clinical characteristics, laboratory analysis, and medication; no differences were seen in the ECR and UC groups.

A limitation of this study is that it did not take into account a full societal approach, potentially underestimating productivity gains for those patients who were still working. However, over the half of the present study population was retired, indicating this underestimation was minimal. The EFEXCARE study was initially designed to assess the costeffectiveness of the implemented ECR concept during a 1-year intervention, which explains why our focus was not to assess changes in physical fitness improvement or changes in risk markers after the intervention. Since the EFEX-CARE study was mainly home-based and the exercise training program was rather intensive, a high number of patients were excluded due to serious co-morbidities. Moreover, almost $38 \%$ of the patients in the EFEXCARE study were not willing to participate in the exercise intervention although they were suitable. Typically, patients who have, for example, very low 


\section{Hautala et al.}

exercise capacity or a fear of exercise after a cardiac event are not willing to participate in exercise interventions. Therefore, the patient sample in the EFEX-CARE study may be partly selected, which could limit generalizability to a broader population of ACS patients with significant co-morbidities.

\section{Perspective}

The present economic evaluation of exercise-based cardiac rehabilitation shows that exercise-based cardiac rehabilitation implemented according to current guidelines is less costly and more effective than UC in ACS patients. Exercise-based cardiac rehabilitation should be implemented for all suitable patients with CAD. These results are useful for policy-makers charged with deciding how limited health care resources should be allocated best in this era of exploding needs.
Key words: Coronary heart disease, cost-effectiveness, exercise training, rehabilitation.

\section{Acknowledgements}

This study was supported by a grant from the Academy of Finland and by the Organisation for Respiratory Health in Finland. The authors appreciate the technical support received from HUR Oy (Kokkola, Finland) and Polar Electro Oy (Kempele, Finland). The authors would also like to thank registered nurses Pirkko Huikuri, Päivi Koski, Päivi Kastell, and Sari Kaarlenkaski, Oulu University Hospital (Oulu, Finland), for their excellent work and assistance throughout this study.

\section{Conflict of interest}

JMA is a partner of ESiOR Oy, which provides health economic and outcome research services to pharmaceutical and medical device companies. The other authors report no conflicts of interest.

\section{References}

Ades PA, Huang D, Weaver SO. Cardiac rehabilitation participation predicts lower rehospitalization costs. Am Heart J 1992: 123: 916921.

Ades PA, Pashkow FJ, Nestor JR. Cost-effectiveness of cardiac rehabilitation after myocardial infarction. J Cardiopulm Rehabil 1997: 17: 222-231.

Alanne S, Roine RP, Rasanen P, Vainiola T, Sintonen H. Estimating the minimum important change in the 15D scores. Qual Life Res 2015: 24: 599-606.

Anderson L, Taylor RS. Cardiac rehabilitation for people with heart disease: an overview of Cochrane systematic reviews. Cochrane Database Syst Rev 2014: 12: CD011273.

Bohmer E, Kristiansen IS, Arnesen H, Halvorsen S. Health-related quality of life after myocardial infarction, does choice of method make a difference? Scand Cardiovasc J 2014: 48: 216-222.

Borg GA. Psychophysical bases of perceived exertion. Med Sci Sports Exerc 1982: 14: 377-381.

Cook RJ, Sackett DL. The number needed to treat: a clinically useful measure of treatment effect. BMJ 1995: 310: 452-454.

Corra U, Piepoli MF, Carre F, Heuschmann P, Hoffmann U, Verschuren M, Halcox J, Giannuzzi P, Saner H, Wood D, Piepoli MF, Corra U, Benzer W, BjarnasonWehrens B, Dendale P, Gaita D, McGee H, Mendes M, Niebauer J,
Zwisler AD, Schmid JP. Secondary prevention through cardiac rehabilitation: physical activity counselling and exercise training: key components of the position paper from the Cardiac Rehabilitation Section of the European Association of Cardiovascular Prevention and Rehabilitation. Eur Heart J 2010: 31: 1967-1974.

Davies P, Taylor F, Beswick A, Wise F, Moxham T, Rees K, Ebrahim S. Promoting patient uptake and adherence in cardiac rehabilitation. Cochrane Database Syst Rev 2010: ???: CD007131.

De Smedt D, Kotseva K, De Bacquer D, Wood D, De Backer G, Dallongeville J, Seppo L, Pajak A, Reiner Z, Vanuzzo D, Georgiev B, Gotcheva N, Annemans L. Costeffectiveness of optimizing prevention in patients with coronary heart disease: the EUROASPIRE III health economics project. Eur Heart J 2012: 33: 2865-2872.

Fenwick E, O'Brien BJ, Briggs A. Cost-effectiveness acceptability curves-facts, fallacies and frequently asked questions. Health Econ 2004: 13: 405-415.

Fletcher GF, Ades PA, Kligfield P, Arena R, Balady GJ, Bittner VA, Coke LA, Fleg JL, Forman DE, Gerber TC, Gulati M, Madan K, Rhodes J, Thompson PD, Williams MA. Exercise standards for testing and training: a scientific statement from the American Heart Association. Circulation 2013: 128: 873-934.
Foster C. Monitoring training in athletes with reference to overtraining syndrome. Med Sci Sports Exerc 1998: 30: 1164-1168.

Frederix I, Hansen D, Coninx K, Vandervoort P, Vandijck D, Hens N, Van Craenenbroeck E, Van Driessche N, Dendale P. Effect of comprehensive cardiac telerehabilitation on one-year cardiovascular rehospitalization rate, medical costs and quality of life: a cost-effectiveness analysis. Eur J Prev Cardiol 2015: ???: ???-???.

Hambrecht R, Walther C, MobiusWinkler S, Gielen S, Linke A, Conradi K, Erbs S, Kluge R, Kendziorra K, Sabri O, Sick P, Schuler G. Percutaneous coronary angioplasty compared with exercise training in patients with stable coronary artery disease: a randomized trial. Circulation 2004: 109: 1371-1378.

Hammill BG, Curtis LH, Schulman KA, Whellan DJ. Relationship between cardiac rehabilitation and long-term risks of death and myocardial infarction among elderly Medicare beneficiaries. Circulation 2010: 121: 63-70.

Hautala AJ, Kiviniemi AM, Karjalainen JJ, Piira OP, Lepojarvi S, Makikallio T, Huikuri HV, Tulppo MP. Peak exercise capacity prediction from a submaximal exercise test in coronary artery disease patients. Front Physiol 2013: 4: 243.

Heran BS, Chen JM, Ebrahim S, Moxham T, Oldridge N, Rees K, 
Thompson DR, Taylor RS. Exercisebased cardiac rehabilitation for coronary heart disease. Cochrane Database Syst Rev 2011: ???: CD001800.

Hujanen T, Mikkola $\mathrm{H}$. Työterveyshuollon palvelujen kustannusten alueelliset erot. Kelan tutkimusosaston julkaisuja 2013: Nettityöpapereita 42. ?????: ?????, 2013.

Jolliffe JA, Rees K, Taylor RS, Thompson D, Oldridge N, Ebrahim S. Exercise-based rehabilitation for coronary heart disease. Cochrane Database Syst Rev 2001: ???: CD001800.

arjalainen JJ, Kiviniemi AM, Hautala AJ, Piira OP, Lepojarvi ES, Peltola MA, Ukkola OH, Hedberg PS, Huikuri HV, Tulppo MP. Determinants and prognostic value of cardiovascular autonomic function in coronary artery disease patients with and without type 2 diabetes. Diabetes Care 2014: 37: 286-294.

Karmali KN, Davies P, Taylor F, Beswick A, Martin N, Ebrahim S. Promoting patient uptake and adherence in cardiac rehabilitation. Cochrane Database Syst Rev 2014: 6: CD007131.

Kattainen E, Merilainen P, Sintonen $\mathrm{H}$. Sense of coherence and healthrelated quality of life among patients undergoing coronary artery bypass grafting or angioplasty. Eur $\mathbf{J}$ Cardiovasc Nurs 2006: 5: 21-30.

Kontodimopoulos N, Pappa E, Chadjiapostolou Z, Arvanitaki E, Papadopoulos AA, Niakas D. Comparing the sensitivity of EQ-5D, SF-6D and 15D utilities to the specific effect of diabetic complications. Eur J Health Econ 2012: 13: 111-120.

Kotseva K, Wood D, De Backer G, De Bacquer D, Group E.I.S. Use and effects of cardiac rehabilitation in patients with coronary heart disease: results from the EUROASPIRE III survey. Eur J Prev Cardiol 2013: 20: 817-826.
Laupacis A, Sackett DL, Roberts RS. An assessment of clinically useful measures of the consequences of treatment. N Engl J Med 1988: 318: 1728-1733.

Lawler PR, Filion KB, Eisenberg MJ. Efficacy of exercise-based cardiac rehabilitation post-myocardial infarction: a systematic review and meta-analysis of randomized controlled trials. Am Heart J 2011: 162: $571-584$ e2.

Manca A, Hawkins N, Sculpher MJ. Estimating mean QALYs in trialbased cost-effectiveness analysis: the importance of controlling for baseline utility. Health Econ 2005: 14: 487-496.

Marzolini S, Brooks D, Oh PI. Sex differences in completion of a 12 month cardiac rehabilitation programme: an analysis of 5922 women and men. Eur J Cardiovasc Prev Rehabil 2008: 15: 698-703.

Nabel EG, Braunwald E. A tale of coronary artery disease and myocardial infarction. N Engl J Med 2012: 366: 54-63.

Oldridge N, Furlong W, Perkins A, Feeny D, Torrance GW. Community or patient preferences for costeffectiveness of cardiac rehabilitation: does it matter? Eur J Cardiovasc Prev Rehabil 2008: 15: 608-615.

Pack QR, Mansour M, Barboza JS, Hibner BA, Mahan MG, Ehrman JK, Vanzant MA, Schairer JR, Keteyian SJ. An early appointment to outpatient cardiac rehabilitation at hospital discharge improves attendance at orientation: a randomized, single-blind, controlled trial. Circulation 2013: 127: 349-355.

Porela P, Mantyla P, Blek-Vehkaluoto M, Ilveskoski E, Juvonen T, Kujanpaa T, Loimaala A, Meinander T, Maenpaa E, Romppanen H, Saraste A, Tierala JI, Tiivistelma. [Update on current care guidelines. Current care guideline: stable coronary artery disease]. Duodecim 2015: 131: $967-$ 968.

Saarni SI, Harkanen T, Sintonen H, Suvisaari J, Koskinen S, Aromaa A, Lonnqvist J. The impact of 29 chronic conditions on health-related quality of life: a general population survey in Finland using 15D and EQ-5D. Qual Life Res 2006: 15: 1403-1414.

Salo H, Sintonen H. [Economic evaluation of an immunization program]. Duodecim 2002: 118:93-97.

Salokangas RK, Poutanen O, Stengard E. Screening for depression in primary care. Development and validation of the Depression Scale, a screening instrument for depression. Acta Psychiatr Scand 1995: 92: 10-16.

Sanderson BK, Phillips MM, Gerald L, DiLillo V, Bittner V. Factors associated with the failure of patients to complete cardiac rehabilitation for medical and nonmedical reasons. J Cardiopulm Rehabil 2003: 23: 281289.

Schwaab B, Waldmann A, Katalinic A, Sheikhzadeh A, Raspe H. In-patient cardiac rehabilitation versus medical care - a prospective multicentre controlled 12 months follow-up in patients with coronary heart disease. Eur J Cardiovasc Prev Rehabil 2011: 18: 581-586.

Sintonen H. The 15D instrument of health-related quality of life: properties and applications. Ann Med 2001: 33: 328-336.

Taylor RS, Brown A, Ebrahim S, Jolliffe J, Noorani H, Rees K, Skidmore B, Stone JA, Thompson DR, Oldridge N. Exercise-based rehabilitation for patients with coronary heart disease: systematic review and meta-analysis of randomized controlled trials. Am J Med 2004: 116: 682-692.

Wong WP, Feng J, Pwee KH, Lim J. A systematic review of economic evaluations of cardiac rehabilitation. BMC Health Serv Res 2012: 12: 243. 


\section{Author Query Form}

\section{Journal: $\quad$ SMS}

Article: $\quad 12738$

Dear Author,

During the copy-editing of your paper, the following queries arose. Please respond to these by marking up your proofs with the necessary changes/additions. Please write your answers on the query sheet if there is insufficient space on the page proofs. Please write clearly and follow the conventions shown on the attached corrections sheet. If returning the proof by fax do not write too close to the paper's edge. Please remember that illegible mark-ups may delay publication.

Many thanks for your assistance.

\begin{tabular}{|l|l|l|}
\hline Query reference & Query & Remarks \\
\hline 1 & $\begin{array}{l}\text { AUTHOR: Please confirm that given names (red) and surnames/family } \\
\text { names (green) have been identified correctly. }\end{array}$ & \\
\hline 2 & AUTHOR: Please provide Fax number for the corresponding author. & \\
\hline 3 & $\begin{array}{l}\text { AUTHOR: Please provide the volume number for reference Davies et al. } \\
(2010) .\end{array}$ & \\
\hline 4 & $\begin{array}{l}\text { AUTHOR: Please provide the volume number and page range for } \\
\text { reference Frederix et al. (2015). }\end{array}$ & \\
\hline 5 & $\begin{array}{l}\text { AUTHOR: Please provide the volume number for reference Heran et al. } \\
\text { (2011). }\end{array}$ & \\
\hline 6 & $\begin{array}{l}\text { AUTHOR: Please provide the publisher name and location for reference } \\
\text { Hujanen and Mikkola (2013). }\end{array}$ & \\
\hline 7 & $\begin{array}{l}\text { AUTHOR: Please provide the volume number for reference Jolliffe et al. } \\
\text { (2001). }\end{array}$ & \\
\hline
\end{tabular}




\section{Please correct and return this set}

Please use the proof correction marks shown below for all alterations and corrections. If you wish to return your proof by fax you should ensure that all amendments are written clearly in dark ink and are made well within the page margins.

\begin{tabular}{|c|c|c|}
\hline Instruction to printer & Textual mark & Marginal mark \\
\hline Leave unchanged & ... under matter to remain & ( \\
\hline $\begin{array}{l}\text { Insert in text the matter } \\
\text { indicated in the margin }\end{array}$ & $h$ & $\begin{array}{l}\text { New matter followed by } \\
h \text { or } h \otimes\end{array}$ \\
\hline Delete & $\begin{array}{l}\text { I through single character, rule or underline } \\
\text { or }\end{array}$ & $\sigma$ or $\sigma / \otimes$ \\
\hline $\begin{array}{l}\text { Substitute character or } \\
\text { substitute part of one or } \\
\text { more word(s) }\end{array}$ & / through letter or & $\begin{array}{l}\text { new character / or } \\
\text { new characters / }\end{array}$ \\
\hline Change to italics & — under matter to be changed & $\leftarrow$ \\
\hline Change to capitals & $\equiv$ under matter to be changed & $\equiv$ \\
\hline Change to small capitals & $=$ under matter to be changed & $=$ \\
\hline Change to bold type & $\sim$ under matter to be changed & $\sim$ \\
\hline Change to bold italic & $\approx$ under matter to be changed & $\underline{s i n}$ \\
\hline Change to lower case & Encircle matter to be changed & $\not$ \\
\hline Change italic to upright type & (As above) & \\
\hline Change bold to non-bold type & (As above) & \\
\hline Insert 'superior' character & $\begin{array}{l}\text { I through character or } \\
K \text { where required }\end{array}$ & $\begin{array}{l}y^{\prime} \text { or } y \\
\text { under character } \\
\text { e.g. } y^{2} \text { or } y^{2}\end{array}$ \\
\hline Insert 'inferior' character & (As above) & $\begin{array}{l}\text { L } \\
\text { over character } \\
\text { e.g. } \hat{\imath}\end{array}$ \\
\hline Insert full stop & (As above) & $\odot$ \\
\hline Insert comma & (As above) & , \\
\hline Insert single quotation marks & (As above) & $\begin{array}{l}\dot{y} \text { or } \dot{X} \text { and/or } \\
\dot{y} \text { or } \dot{X}\end{array}$ \\
\hline Insert double quotation marks & (As above) & $\begin{array}{l}\ddot{y} \text { or } \ddot{y} \text { and/or } \\
\ddot{y} \text { or } \ddot{x}\end{array}$ \\
\hline Insert hyphen & (As above) & $1-1$ \\
\hline Start new paragraph & $\digamma$ & 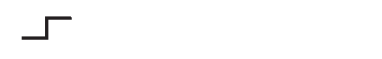 \\
\hline No new paragraph & $\infty$ & $\omega$ \\
\hline Transpose & $\sqcup$ & ᄃ \\
\hline Close up & linking $\bigcirc$ characters & \\
\hline $\begin{array}{l}\text { Insert or substitute space } \\
\text { between characters or words }\end{array}$ & $\begin{array}{l}\text { I through character or } \\
\Lambda \text { where required }\end{array}$ & \\
\hline $\begin{array}{l}\text { Reduce space between } \\
\text { characters or words }\end{array}$ & $\begin{array}{l}\text { between characters or } \\
\text { words affected }\end{array}$ & $\uparrow$ \\
\hline
\end{tabular}

